\title{
Pesticide exposure in honey bees results in increased levels of the gut pathogen Nosema
}

\author{
Jeffery S. Pettis • Dennis vanEngelsdorp • \\ Josephine Johnson • Galen Dively
}

Received: 1 May 2011 /Revised: 25 December 2011 / Accepted: 31 December 2011 / Published online: 13 January 2012

(C) The Author(s) 2012. This article is published with open access at Springerlink.com

\begin{abstract}
Global pollinator declines have been attributed to habitat destruction, pesticide use, and climate change or some combination of these factors, and managed honey bees, Apis mellifera, are part of worldwide pollinator declines. Here we exposed honey bee colonies during three brood generations to sub-lethal doses of a widely used pesticide, imidacloprid, and then subsequently challenged newly emerged bees with the gut parasite, Nosema spp. The pesticide dosages used were below levels demonstrated to cause effects on longevity or foraging in adult honey bees. Nosema infections increased significantly in the bees from pesticide-treated hives when compared to bees from control hives demonstrating an indirect effect of pesticides on pathogen growth in honey bees. We clearly demonstrate an increase in pathogen growth within individual bees reared in colonies exposed to one of the most widely used pesticides worldwide, imidacloprid, at below levels considered harmful to bees. The finding that individual bees with undetectable levels of the target pesticide, after being reared in a sub-lethal pesticide environment within the
\end{abstract}

Communicated by: Sven Thatje

J. S. Pettis $(\square)$

USDA-ARS Bee Research Laboratory,

Beltsville, MD, USA

e-mail: jeff.pettis@ars.usda.gov

D. vanEngelsdorp

Department of Entomology, University of Maryland,

College Park, MD, USA

J. Johnson

Department of Toxicology, University of Maryland Baltimore,

Baltimore, MD, USA

G. Dively

Department of Entomology, University of Maryland,

College Park, MD, USA colony, had higher Nosema is significant. Interactions between pesticides and pathogens could be a major contributor to increased mortality of honey bee colonies, including colony collapse disorder, and other pollinator declines worldwide.

Keywords Apis mellifera Imidacloprid - Nosema .

Sub-lethal $\cdot$ Pesticides $\cdot$ Pathogens

\section{Introduction}

The honey bee, Apis mellifera, is arguably the most important pollinator of agricultural crops (Klein et al. 2007). While worldwide managed honey bee populations have increased over the last 50 years, colony populations have decreased significantly in many European and North American nations (Aizen and Harder 2009) as a result of habitat destruction, pesticide use, pathogens, and climate change (NRC 2007) or some combination of these factors (vanEngelsdorp and Meixner 2010). At the same time, cultivation of crops that are dependent on insects for pollination (Aizen et al. 2009) has increased. The ability to provide sufficient colonies to meet this anticipated demand is questionable, especially in light of the elevated losses experienced by US beekeepers over the winters of 2006/2007 and 2007/2008 (vanEngelsdorp et al. 2007; vanEngelsdorp et al. 2008). Colonies that die with a condition known as colony collapse disorder (CCD) make up a significant proportion of recent overwintering losses in the USA (vanEngelsdorp et al. 2008). While the cause of CCD remains unknown, affected colonies are often infected with a greater variety and higher loads of disease agents than apparently healthy colonies (Johnson et al. 2009; vanEngelsdorp et al. 2009a; Cox-Foster et al. 2007). This suggests that some factor or combination of factors may be weakening bees by making them more susceptible to infection (vanEngelsdorp et al. 
2009a). A myriad of abiotic and biotic factors can adversely affect the ability of honey bees to fight infection, including interactions between disease agents, mite parasitism, poor nutrition, and sub-lethal exposure to pesticides (Johnson et al. 2009; vanEngelsdorp et al. 2009a). Systemic pesticides such as imidacloprid pose a new route of exposure in pollen and nectar and have been demonstrated to have negative effects on learning in adult bees (Decourtye et al. 2004).

Here we test the hypothesis that bees exposed to sub-lethal levels of pesticide are more susceptible to disease. We exposed colonies of honey bees to the insecticide imidacloprid at sub-lethal levels and then challenged newly emerged workers from those colonies with the gut parasite Nosema spp., two species (Nosema apis and Nosema ceranae) of which are known to adversely affect colony health (Higes et al. 2008; Kauko et al. 2003). The pesticide dosages used were below levels demonstrated to cause effects on longevity or foraging in adult honey bees (Maus et al. 2003; Bonmatin et al. 2007; Deseneux et al. 2007).

\section{Materials and methods}

For 10 weeks, we continually exposed full sized colonies of bees (30-40,000 adults) to 5 and 20 ppb imidacloprid by provisioning colonies with protein supplement patties spiked with the pesticide. After 5 and 8 weeks of exposure (ca. 1.5 and 2.5 generations of exposure), wax combs with emerging brood were taken into the laboratory and groups of newly emerged adult bees from selected colonies were removed and either used to determine fresh weight or caged and fed a suspension containing spores of the known bee pathogens $N$. apis and $N$. ceranae over the first 2 days of adult life. Ten days later, bees were sacrificed and the development of Nosema infection in individual bees determined.

\section{Chronic imidacloprid exposure to colonies}

Thirty honey bee colonies were used and divided into three treatment groups of ten colonies each. Colonies were established in April 2008 in five apiaries, approximately $0.5 \mathrm{~km}$ apart containing two colonies from each treatment group (total colonies per apiary $=6)$. Packages of bees $(1.8 \mathrm{~kg})$ were installed in new hive equipment including frames with waxcoated plastic foundation. All queens established in study colonies came from the same genetic source. All colonies were managed to limit the levels of other pests and pathogens. All colonies were fed equal amounts of sucrose syrup until natural forage was abundant in May. Treatments consisted of untreated Megabee ${ }^{\circledR}$ protein patties $(100 \mathrm{~g}$ each) or patties containing 5 and $20 \mathrm{ppb}$ of imidacloprid made by mixing neat material with the sucrose solution used to make the protein patties. Samples were taken of fresh treated protein patties and analyzed for imidacloprid content to insure proper delivery of the target dose. Beginning in May 2008, each colony received four 80 -g patties per week for 10 weeks. Unconsumed patties were removed after 7 days, weighed to measure consumption, and replaced with new treatment protein patties. Adult bees and stored pollen "bee bread" were collected 1 week after the 10 -week feeding period and analyzed for imidacloprid levels. Samples ( $>5 \mathrm{~g}$ ) of newly emerged bees and random-aged bees from each experimental hive and protein patties from each treatment group were all analyzed for imidacloprid levels at the USDA-AMS laboratory in Gastonia, NC, using GC/MS with a limit of detection of $0.1 \mathrm{ppb}$.

\section{Experimental bees and pathogen challenge}

Five weeks into treatment in July 2008, a single brood frame with emerging worker bees were removed from each of three to four colonies treatment and held in an incubator at $34^{\circ} \mathrm{C}$ overnight. Newly emerged bees were collected the next morning and placed in groups of 30 bees per cage for Nosema challenge. An additional 20 newly emerged bees per colony were weighed to determine average emerged bee weight. A Nosema spore suspension was made by taking the mid-guts of ten workers from a single Nosema-infected colony and macerating the guts in $10 \mathrm{ml}$ of water and determining the total spore count using the methods of Cantwell (1970) and a hemocytometer slide. The spore suspension was then centrifuged for $10 \mathrm{~min}$ at 3,000 rpm, the supernatant discarded, and the spore pellet resuspended using a 50:50 volume to volume sucrose solution to reach a final spore concentration of one million spores per milliliter of solution. Ten milliliters of this solution was fed to each cage of 30 bees over the first 2 days of adult life and after complete consumption of the $10 \mathrm{ml}$ each bee received an approximate dose of 333,333 spores over 2 days. Treated bees were allowed to age in cages for 12 days, sacrificed, and spore levels determined for each bee using standard light microscopy and a hemocytometer after the methods of Cantwell (1970). Nosema spore data was log transformed prior to analysis to meet statistical assumptions. Mortality was monitored daily and no cage exceeded 20\% over 12 days. At day 12, ten randomly selected live bees were used for spore determination on an individual bee basis. A second trial was conducted in August, 8 weeks into treatment and this time however emerged bees were feed $10 \mathrm{ml}$ of sugar solution containing either 0 (control), 0.1 , or 1 million spores per milliliter to explore potential effects of inoculum dose of pathogen growth. The Nosema spore suspension was made using bees from the same source colony as before. Mortality in the cages averaged less than $20 \%$ after 12 days. Samples of the Nosema spore suspensions from both dates were analyzed for species composition using established molecular methods (Chen et al. 2008) and found to be predominantly $N$. ceranae but a weak band corresponding to $N$. apis was also detected 
indicating a mixed co-infection of the two species which is still quite common (Chen et al. 2008).

\section{Results}

A pronounced increase in Nosema growth was evident within individual bees reared in colonies exposed to a low, sub-lethal level of the pesticide imidacloprid. Two trials were conducted in this experiment. In the first trial, in July, ten newly emerged bees from each of three control colonies, four colonies feed high levels of imidacloprid, and two colonies feed with low levels of imidacloprid (inconsistent emergence of adult bees from brood combs in the low group resulted in an unbalanced design by treatment for this trial) were fed 1 million spores per milliliters of sugar syrup (ca. 333,333 spores per bee) and had Nosema spore counts quantified 12 days after emergence. Bees originating from colonies feed high and low levels of imidacloprid had higher Nosema spore counts than controls (ANOVA, $F=7.34$, d.f. $=$ 2, 70, $P=0.0013$; Fig. 1). In the second trial, in August, newly emerging bees from nine different colonies, distinct from the colonies used in trial one (three feed with high levels of imidacloprid, three low levels of imidacloprid, and three control colonies) were collected. Ten bees from each cage (colony) were examined for spore counts on day 12 . While the presence of spores had the expected effect of increasing spore levels in Nosema spore feed bees (ANOVA, $F=26.41$, d.f. $=2,357, P<0.0001$ ), no difference was observed in the final spore counts in bees feed different doses of Nosema (Tukey's HDS test; Fig. 2). We therefore combined the data from both dosage replicates for further analysis. Bees

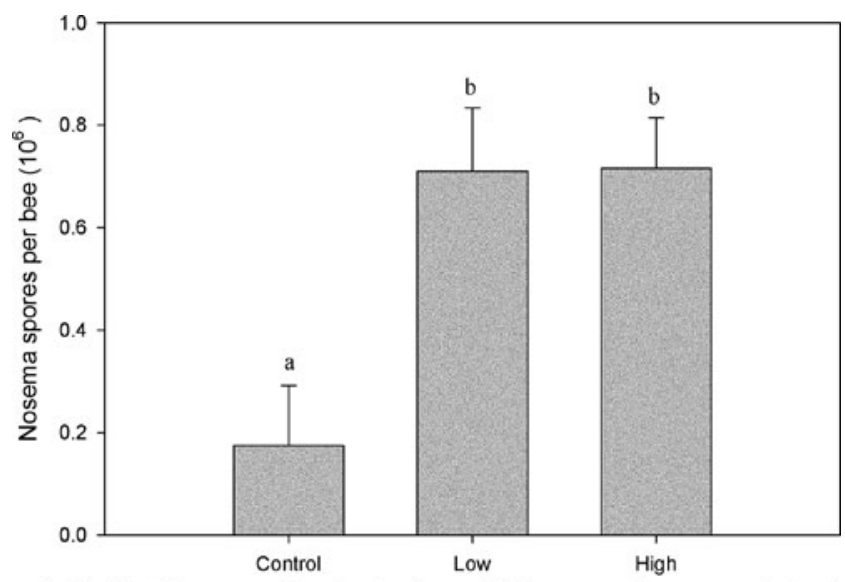

Imidacloprid exposure in colonies from which emerged bees were derived

Fig. 1 Total Nosema spore count in 12-day-old bees derived from colonies feed high, low, and no levels of imidacloprid (July, trial 1). Immature bees were removed from colonies, allowed to emerge, and feed sugar solution with $10^{6}$ Nosema spores per milliliter of sugar syrup. Columns with different letters are significantly different from each other (Tukey HSD test $P<0.05$ )

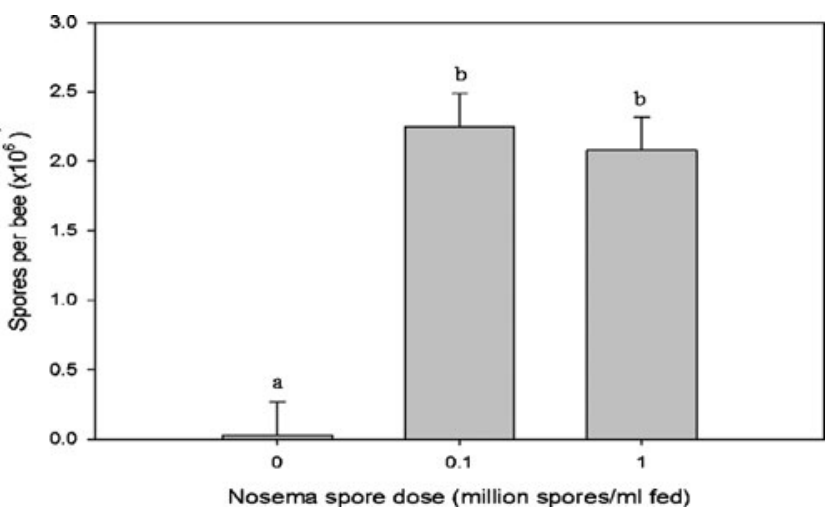

Fig. 2 Total spore count in 12-day-old bees fed two different levels of Nosema spores following adult emergence. Columns with different letters are significantly different from each other (Tukey HSD test $P<0.05$ )

in trial 2 originating from colonies chronically exposed to imidacloprid, had higher levels of Nosema spores 12 days after being feed Nosema spores than bees originating from control colonies fed the same Nosema spore solution, consistent with the results from trial 1 (ANOVA, $F=14.85$, d.f. $=4$, $355, P<0.0001$; Fig. 3). Our total colony sample size across the two trials was controls $n=6$, low $n=5$, and high $n=7$ distinct colonies tested of the 30 total colonies. A few colonies lost queens and or had limited brood which prevented inclusion in the laboratory studies.

We verified pesticide exposure to colonies by measuring the weekly consumption of the treated protein patties and by analyzing the level of imidacloprid in stored bee bread and random-aged bees removed from colonies 1 week after the exposure period (Table 1). Daily protein patty consumption averaged $29.0 \pm 0.84,29.3 \pm 0.78$, and $31.1 \pm 0.85 \mathrm{~g}$ for the

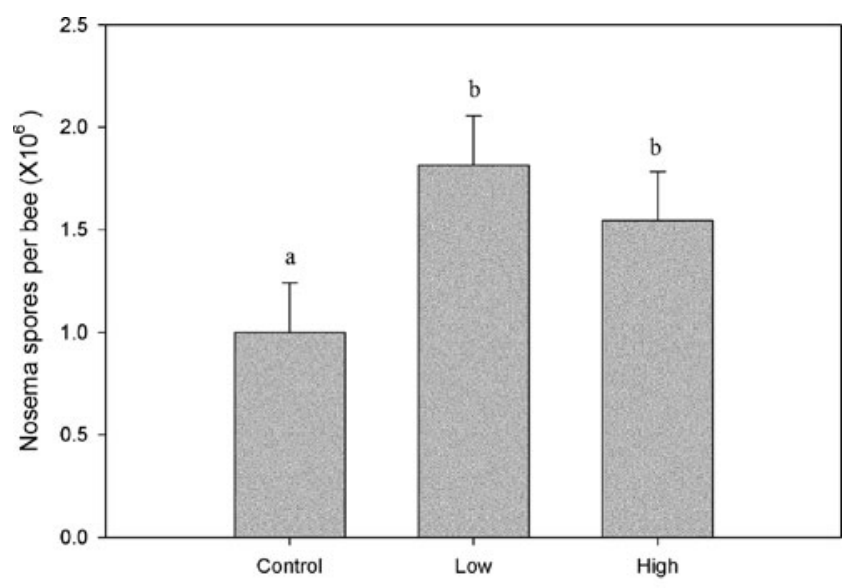

Imidacloprid exposure in colonies from which emerged bees were derived

Fig. 3 Total Nosema spore count in 12-day-old bees derived from colonies feed high, low, and no levels of imidacloprid (August, trial 2). Immature bees were removed from colonies, allowed to emerge, and feed sugar solution with known amounts of spores (see text for details). Columns with different letters are significantly different from each other (Tukey HSD test $P<0.05$ ) 
Table 1 Levels of imidacloprid in bee bread (stored pollen/protein patties) and random-aged worker bees from experimental colonies and average weights of newly emerged bees from the three colony treatments for trials 1 and 2 in July and August 2008, respectively ( $n=20$ bees/hive)

\begin{tabular}{|c|c|c|c|c|c|}
\hline \multirow[b]{2}{*}{$\begin{array}{l}\text { Treatment } \\
\text { colonies }\end{array}$} & \multicolumn{3}{|c|}{ Imidacloprid levels $^{\mathrm{a}}$ (mean $\pm \mathrm{SEM}, \mathrm{ppb}$ ) } & \multicolumn{2}{|c|}{ Emerged bee weight (mean \pm SEM, $n=20$ bees $^{\mathrm{d}}$ ) } \\
\hline & $\begin{array}{l}\text { Bee bread from } \\
\text { colonies }^{\text {b }}\end{array}$ & $\begin{array}{l}\text { Random-aged } \\
\text { bees from colonies }\end{array}$ & $\begin{array}{l}\text { Imid. level } \\
\text { emerged bees }\end{array}$ & $\begin{array}{l}\text { Emerged bee } \\
\text { weight }(\mathrm{g}) \text { July trial } 1\end{array}$ & $\begin{array}{l}\text { Emerged bee } \\
\text { weight (g) Aug. Trial } 2\end{array}$ \\
\hline Control & $0.20 \pm 0.22$ & $0.6 \pm 0.31$ & Not detected & $0.115 \pm 0.0014$ & $0.116 \pm 0.0018$ \\
\hline Low $5 \mathrm{ppb}$ & $1.62 \pm 0.68$ & $1.58 \pm 0.68$ & Not detected & $0.112 \pm 0.0016$ & $0.116 \pm 0.0017$ \\
\hline High $20 \mathrm{ppb}$ & $3.49 \pm 1.55$ & $3.67 \pm 1.48$ & Not detected & $* 0.106 \pm 0.0017$ & $0.116 \pm 0.0020$ \\
\hline
\end{tabular}

$* P<0.05$ (indicate significant differences in emerged bee weights when compared to control hives in the same trial)

${ }^{\mathrm{a}}$ Limit of detection is $0.1 \mathrm{ppb}$

${ }^{\mathrm{b}}$ Sample size $n=10$ patties sampled

${ }^{\mathrm{c}}$ Newly emerged bees from both trials were tested for imidacloprid

${ }^{\mathrm{d}}$ One control cage, July trial, had only 11 bees available to weigh, all others $n=20$ bees

control, 5 and $20 \mathrm{ppb}$ colonies, respectively, and was not significantly different among treatments (ANOVA, $F=0.83$, d.f. $=2,7, P=0.39$ ). Residues of imidacloprid were found in bee bread and bees from exposed colonies and increased in direct and expected proportion to the concentrations in the treated protein patties (Table 1). We also found traces of imidacloprid in bees and bee bread collected from control colonies. This imidacloprid exposure in our controls may have been the result of bee drift between experimental colonies and/or from exposure resulting from foraging on treated agricultural crops in the vicinity. Newly emerged bees tested negative for imidacloprid and bees from the higher 20-ppb pesticide exposure colonies were significantly lighter in weight in the July trial (Table 1). Similar effects of reduced weight were documented in queen bees exposed to another pesticide, coumaphos (Pettis et al. 2004). Bees reared in colonies exposed to imidacloprid and fed sucrose solutions dosed with Nosema spores had significantly higher levels of Nosema infection as compared to bees originating from control colonies (Figs. 1 and 3). The concentration of imidacloprid in protein patties fed to colonies did not have an effect on final Nosema spore counts in 12-day-old bees. Similarly, the dose of Nosema spores provided to emerged bees $(0.1$ or 1 million spores per milliliter of sucrose water) did not affect total spore count in 12-day-old bees (Fig. 2).

The group of 30 colonies that provided experimental bees for cage experiments were in good health as indicated by low mite and disease levels. Only three of these colonies tested positive for Nosema at the beginning of the trial and those three colonies were excluded from use. At the end of 10 weeks, eight of 30 tested positive for Nosema but there was surprisingly no relationship between Nosema infection and imidacloprid treatment which would have been predicted by the lab study. Three control, three $5 \mathrm{ppb}$, and two $20 \mathrm{ppb}$ colonies tested Nosema positive, with average spore counts of 4.3, 2.9, and 0.5 million spores per bee, respectively. Varroa mite counts were low with an average mite count of 0.36 mites/100 bees, well below damaging levels which range from five to ten mites per 100 bees, with 27 of 30 colonies testing positive using 300 adult bees (Lee et al. 2010). No colonies tested were found to have tracheal mites.

\section{Discussion}

We clearly demonstrate an interaction between sub-lethal exposure to imidacloprid at the colony level and the spore production in individual bees of honey bee gut parasite Nosema. Two similar studies have just been published that directly treated individual bees with imidacloprid, fipronil, or thiacloprid and then challenged them with Nosema with similar synergistic interaction between Nosema and pesticide exposure (Alaux et al. 2010; Vidau et al. 2011). Our study differs in several significant ways; (1) our study employed sub-lethal colony-level pesticide chronic exposure instead of laboratory direct exposure to experimental bees, (2) no imidacloprid residues could be found in the newly emerged worker bees challenged in our study (Table 1), (3) our test bees could only have received pesticide exposure during larval development, thus (4) pesticide exposure to test bees could only have been indirectly from brood food from nurse bees (Winston 1987) that were exposed as they fed on imidacloprid-spiked protein. We can only speculate as to why sub-lethal exposure in brood food to larva resulted in increased spore production in adult bees. Since Nosema initiates infection in the mid-gut then perhaps in the larval stages the mid-gut ways altered or weakened in some manner that resulted in increased Nosema infection in adult bees. Vidau et al. (2011) failed to demonstrate a change in the pesticide detoxification system in adult bees yet still demonstrated an increase in mortality in adult bees when pesticides and 
Nosema were combined. Alaux et al. (2010) showed that coexposure to imidacloprid and Nosema weakened bees but they also showed a trend toward a slight decrease in spore production with pesticide exposure. Individual bees in our study showed a marked increase in Nosema spore production in the laboratory but the parent colonies failed to show increased Nosema levels over time. Our understanding of $N$. ceranae at the colony level is still very limited as colony-level spore counts can be highly variable. Perhaps spore production is not the proper way to measure $N$. ceranae infection as has always been the case with $N$. apis? Taken together these three studies clearly demonstrate synergism between pesticides and Nosema. The current study, with the more robust chronic sublethal pesticide exposure at the colony level, clearly demonstrates that such interactions are possible in the real world, not just in a laboratory setting. Additional research is needed to understand the underlying mechanisms of pesticide pathogen interactions. This is especially true in our study in trying to determine how the pesticide moved in the colony, affected nurse bees, and what level of exposure that larvae in these colonies actually received. The pesticide was consumed equally among the two dosages and house bees contained the pesticide but the pharmacokinetics within the colony is yet to be determined.

Past studies have found that chronic, sub-lethal exposure to pesticides can have an adverse effect on colonies (Bendahou et al. 1999) and has been associated with overt disease outbreaks in honey bees (Morse et al. 1965). Conversely, further infection with the chronic bee paralysis virus can affect honey bee tolerance to agricultural pesticides (Bendahou et al. 1997). Recent increases in colony losses in the USA and Europe have drawn particular attention to one relatively new class of systemic pesticides, the neonicotinoids, of which imidacloprid is a member. Beekeeper conviction that imidacloprid is responsible for colony losses in France has resulted in the withdrawal of its registration (under the trade name Gaucho, Bayer, Leverkusen, Germany) as a seed treatment for sunflowers and corn Ministere de l'Agriculture et de la Peche (1999 and 2004). Similar pressure in California has resulted in a reevaluation of four neonicotinoids, including imidacloprid, because of elevated levels of residues in leaves and blossoms of ornamental plants after imidacloprid applications.

The published levels of imidacloprid expressing acute and chronic toxicity on bees are variable and conflicting (Nguyen et al. 2009). Most studies suggest that imidacloprid can cause disorientation and associative learning problems in honey bees at exposure levels above $20 \mathrm{ppb}$ (Decourtye et al. 2004; Deseneux et al. 2007). However, crop residue studies have detected imidacloprid at levels of $2-5 \mathrm{ppb}$ in pollen and $>1.5 \mathrm{ppb}$ in nectar of seed-treated corn, sunflowers, and rape (Kauko et al. 2003) well below the $20 \mathrm{ppb}$ level documented to cause acute and chronic toxicity effects. To our knowledge no studies have examined chronic effects of dietary exposure to imidacloprid in functional colonies over multiple brood cycles and potential synergistic effects of pesticide and disease interactions. Our results suggest that the current methods used to evaluate the potential negative effect of pesticides are inadequate. This is not the first study to note a complex and unexpected interaction between low pesticide exposure and pathogen loads. Trematodes levels in amphibian populations are driven by atrazine in the aquatic environment (Rohr et al. 2008). Elevated levels of the fungicide chlorothalonil in honey bees have been associated with "entombed pollen" which is linked with increased risk of colony mortality (vanEngelsdorp et al. 2009b). The call for a reevaluation of pesticide test protocols required for the registration of products is not new (Colin et al. 2004; Halm et al. 2006). These proposed new standards utilize the Predicated No Effect Concentration which is determined using chronic and acute toxicity data and not potentially indirect effects of pesticide exposure, such as increased susceptibility to pathogens. With the wide variety of pesticides that have been documented in failing beehives (Mullen et al. 2010), it is imperative that we understand both the synergistic effects these compound may have and the interactions with other variables, like pathogens, involved in bee health. We suggest new pesticide testing standards be devised that incorporate increased pathogen susceptibility into the test protocols. Lastly, we believe that subtle interactions between pesticides and pathogens, such as demonstrated here, could be a major contributor to increased mortality of honey bee colonies worldwide.

Acknowledgments These studies were made possible with the help of Nathan Rice, Vic Levi, Mike Embry, Terry Patton, and Amy Miller. Financial support was provided to JSP from the USDA-ARS Areawide Project to improve bee health and to DVE from the Pennsylvania Department of Agriculture, and GD from the North American Pollinator Protection Campaign and Foundation from the Preservation of Honey Bees.

Open Access This article is distributed under the terms of the Creative Commons Attribution Noncommercial License which permits any noncommercial use, distribution, and reproduction in any medium, provided the original author(s) and source are credited.

\section{References}

Aizen MA, Harder LD (2009) The global stock of domesticated honey bees is growing slower then agricultural demand for pollination. Curr Biol 19:915-918

Aizen MA, Garibaldi LA, Cunningham SA, Klein AM (2009) How much does agriculture depend on pollinators? Lessons from longterm trends in crop production. Ann Bot 103:1579-1588

Alaux C, Brunet J-L, Dussaubat C, Mondet F, Tchamitchan S et al (2010) Interactions between Nosema microspores and a neonicotinoid weaken honeybees (Apis mellifera). Environ Microbiol 12:774-782 
Bendahou N, Bounias M, Fleche C (1997) Acute toxicity of cypermethrin and fenitrothion on honeybees (Apis mellifera mellifera) according to age, formulations and (chronic paralysis virus)/insecticide interaction. J Environ Biol 18:55-65

Bendahou N, Fleche C, Bounias M (1999) Biological and biochemical effects of chronic exposure to very low levels of dietary cypermethrin (Cymbush) on honeybee colonies (Hymenoptera: Apidae). Ecotoxicol Environ Saf 44:147-153

Bonmatin JM, Marchand PA, Cotte JF, Aajoud A, Casabianca H et al. (2007) Environmental fate and ecological effects of pesticides. In: delRe AAM, Capri E, Fragoulis G, Trevisan M (eds). 13th Symposium Pesticide Chemistry, Piacenza, Italy, 3-6 September. pp. $827-834$

Cantwell GE (1970) Standard methods for counting Nosema spores. Am Bee J 110:222

Chen Y, Evans JD, Smith IB, Pettis JS (2008) Nosema ceranae is a long-present and wide-spread microsporidian infection of the European honey bee (Apis mellifera) in the United States. J Invertebr Pathol 97:186-188

Colin ME, Bonmatin JM, Moineau I, Gaimon C, Brun S, Vermandere JP (2004) A method to quantify and analyze the foraging activity of honey bees: relevance to the sublethal effects induced by systemic insecticides. Arch Environ Contam Toxicol 47:387-395

Cox-Foster DL, Conlan S, Holmes EC, Palacios G, Evans JD et al (2007) A metagenomic survey of microbes in honey bee colony collapse disorder. Science (Washington) 318:283-286

Ministere de l'Agriculture et de la Peche (1999) Avis aux de' tenteurs et aux utilisateurs de semences de tournesol. J Off Repub Fr. 38

Ministere de l'Agriculture et de la Peche (2004) Avis aux de' tenteurs dÕautorisation de mise sur le marche', aux distributeurs et aux utilisateurs du produit phytopharmaceutique Gaucho. J Off Repub Fr 126

Decourtye A, Devillers J, Cluzeau S, Charreton M, Pham-Delègue M-H (2004) Effects of imidacloprid and deltamethrin on associative learning in honeybees under semi-field and laboratory conditions. Ecotoxicol Environ Saf 57:410-419

Deseneux N, Decourtye A, Delpeuch J-M (2007) The sub-lethal effects of pesticides on beneficial arthropods. Ann Rev Entomol 52:81106

Halm MP, Rortais A, Arnold G, Taséi JN, Rault S (2006) New risk assessment approach for systemic insecticides: the case of honey bees and imidacloprid (Gaucho). Environ Sci Technol 40:24482454

Higes M, Martín-Hernández R, Botías C, Bailón EG, González-Porto AV et al (2008) How natural infection by Nosema ceranae causes honeybee colony collapse. Environ Microbiol 10:2659

Johnson RM, Evans JD, Robinson GE, Berenbaum MR (2009) Changes in transcript abundance relating to colony collapse disorder in honey bees (Apis mellifera). PNAS 106:14790-14795

Kauko L, Honko S, Vartiainen H (2003) Winter mortality and Nosema apis Z. The diagnostic value of Nosema spore counts - a clinical approach. Ann Univ Mariae Curie-Sklodowska Sect DD 58:199 203
Klein A-M, Vaissière BE, Cane JH, Steffan-Dewenter I, Cunningham SA et al (2007) Importance of pollinators in changing landscapes for world crops. Proc R Soc Lond B 274:303-313

Lee K, Moon R, Burkness E, Hutchinson W, Spivak M (2010) Practical sampling plans for Varroa destructor (Acarii: Varroidae) in Apis mellifera (Hymenoptera: Apidae) colonies and apiaries. $\mathrm{J}$ Econ Entomol 103:1039-1050

Maus C, Curé G, Schmuck R, Porrini C, Bortolotti L (2003) Safety of imidacloprid seed dressings to honey bees: a comprehensive overview and compilation of the current state of knowledge. Bull Insectol 56:51-57

Morse RA, Dyce EJ, Gould AC (1965) The treatment of American foulbrood in New York state. Bee World 46:15-17

Mullen CA, Frazier M, Frazier JL, Ashcraft S, Simonds R, vanEngelsdorp D, Pettis JS (2010) High levels of miticides and agrochemicals in North American apiaries: implications for honey bee health. PLoS One 5(3):e9754. doi:10.1371/journal.pone.0009754

National Research Council (2007) Status of pollinators in North America. National Academy of Sciences, Washington, D.C., p 317

Nguyen BK, Saegerman C, Pirard C, Mignon J, Widart J et al (2009) Does imidacloprid seed-treated maize have an impact on honey bee mortality? J Econ Entomol 102:616-623

Pettis JS, Collins AM, Wilbanks R, Feldlaufer MF (2004) Effects of coumaphos on queen rearing in the honey bee, Apis mellifera. Apidologie 35:605-610

Rohr JR, Schotthoefer AM, Raffel TR, Carrick HJ, Halstead N et al (2008) Agrochemicals increase trematode infections in a declining amphibian species. Nature (London) 455:1235-1239

vanEngelsdorp D, Meixner MD (2010) A historical review of managed honey bee populations in Europe and the United States and the factors that may affect them. J Invertebr Pathol 103:S80-S95

vanEngelsdorp D, Underwood R, Caron D, Hayes J Jr (2007) An estimate of managed colony losses in the winter of 2006-2007: a report commissioned by the Apiary Inspectors of America. Am Bee J 147:599-603

vanEngelsdorp D, Hayes J Jr, Underwood RM, Pettis J (2008) A survey of honey bee colony losses in the U.S., fall 2007 to spring 2008. PLoS One 3:e4071

vanEngelsdorp D, Evans JD, Saegerman C, Mullin C, Haubruge E et al (2009a) Colony collapse disorder: a descriptive study. PLoS One 4:e6481

vanEngelsdorp D, Evans JD, Donovall L, Mullin C, Frazier M et al (2009b) "Entombed pollen": a new condition in honey bee colonies associated with increased risk of colony mortality. J Invertebr Pathol 101:147-149

Vidau C, Diogon M, Aufauvre J, Fontbonne R, Vigues B, Brunet J-L, Texier C, Biron D, Blot N, Alaoui E, Belzunces L, Delbac F (2011) Exposure to sublethal doses of fipronil and thiacloprid highly increases mortality of honeybees previously infected by Nosema ceranae. PLoS One 6(6):e21550. doi:10.1371/journal. pone. 0021550

Winston M (1987) The biology of the honey bee. Harvard University Press, Cambridge, p 267 